\title{
Transferring Ethnopharmacological Results Back to Traditional Healers in Rural Indigenous Communities - The Ugandan Greater Mpigi Region Example
}

Research Translation

Fabien Schultz (corresponding author) | ORCID: OOOO-OOO3-1904-2430 Institute of Biotechnology, Faculty III - Process Sciences, Technical University of Berlin, Berlin, Germany Department of Agriculture and Food Sciences, Neubrandenburg University of Applied Sciences, Neubrandenburg, Germany fabien.schultz@mailbox.tu-berlin.de

Inken Dworak-Schultz

ARUDEVo, Lwengo, Uganda

\section{Alex Olengo}

Department of Plant Sciences, Microbiology and Biotechnology, Makerere University, Kampala,

Godwin Anywar | ORCID: oooo-0oo3-0926-1832

Department of Plant Sciences, Microbiology and Biotechnology,

Makerere University, Kampala, Uganda

\section{Leif-Alexander Garbe}

Department of Agriculture and Food Sciences, Neubrandenburg University of Applied Sciences, Neubrandenburg, Germany

zE LT - Neubrandenburg Center for Nutrition and Food Technology gGmbH, Neubrandenburg, Germany 


\begin{abstract}
In ethnopharmacology, scientists often survey indigenous communities to identify and collect natural remedies such as medicinal plants that are yet to be investigated pharmacologically in a laboratory setting. The Nagoya Protocol provided international agreements on financial benefit sharing. However, what has yet only been poorly defined in these agreements are the non-financial benefits for local intellectual property right owners, such as traditional healers who originally provided the respective ethnomedicinal information. Unfortunately, ethnopharmacologists still rarely return to local communities. In this video article, the authors present a method for transferring results back to traditional healers in rural indigenous communities, taking the authors' previous studies among 39 traditional healers in Uganda as an example. The authors' approach is based on a two-day workshop, and the results are presented as original footage in the video article. The authors' work demonstrated a successful method for ensuring bidirectional benefit and communication while fostering future scientific and community-work collaborations. The authors believe it is the moral duty of ethnopharmacologists to contribute to knowledge transfer and feedback once a study is completed. The workshop method, as an example for science outreach, might also be regarded as a valuable contribution to research on education theory and science communication.
\end{abstract}

\title{
Keywords
}

research translation - ethnopharmacology - traditional medicine - traditional healers - workshop - Mpigi - transfer of results - Uganda - medicinal plants

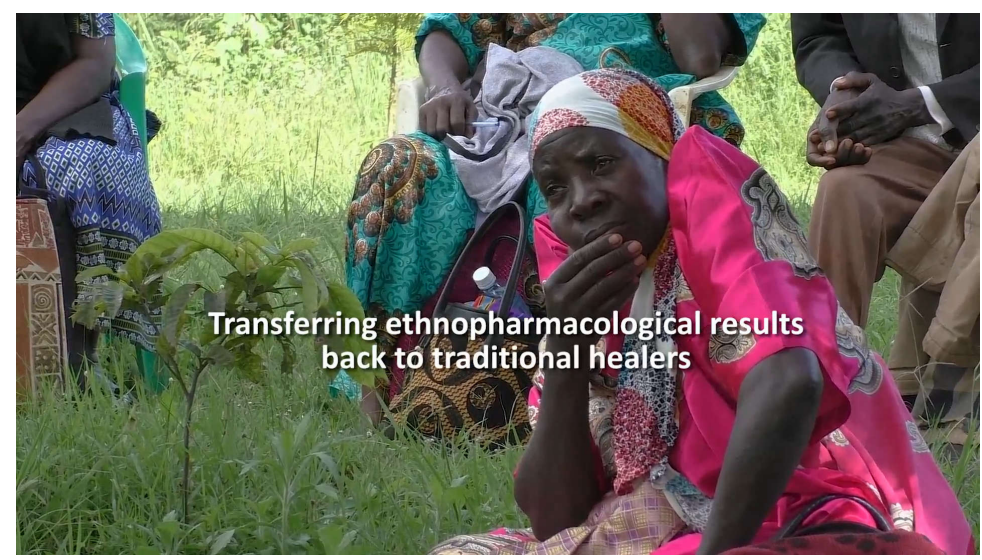

FEATURE This article comprises a video, which can be viewed here. 
Across the globe and throughout history, plants have been used by humans as a source of medicine and natural remedies (Bussmann et al., 2018; Kigen et al., 2019). The World Health Organization defines traditional medicine as "the knowledge, skills and practices based on the theories, beliefs and experiences indigenous to different cultures, used in the maintenance of health and in the prevention, diagnosis, improvement or treatment of physical and mental illness." (wHO, 2019) Traditional medicine continues to be of great importance to all human beings (Yuan et al., 2016). In the developing world, over $80 \%$ of the population still relies on medicinal plants as their primary source of healthcare (Bussmann et al., 2018; Kigen et al., 2019; F. Schultz et al., 2020; WHO, 2010). Even in the modern Western pharmaceutical industry, traditional medicine still plays a key role in drug discovery (Atanasov et al., 2015; Balunas \& Kinghorn, 2005; Heinrich et al., 2015; Porras et al., 2020; Fabien Schultz, Godwin Anywar, Huaqiao Tang, et al., 2020). For instance, nearly $50 \%$ of all drugs that are currently FDA-approved in the US have been derived directly or indirectly from natural sources (Li et al., 2019; Veeresham, 2012).

Here, the science of ethnopharmacology seeks to investigate the medicinal use of plants, animals, macrofungi, microorganisms, and minerals through pharmacological, socio-cultural, and anthropological methods. Ethnopharmacology is a highly interdisciplinary field of research (Heinrich, 2014; Heinrich \& Jäger, 2015), encompassing a) field studies (such as ethnobotanical studies in local communities, interviews, surveys, and the first time documentation of medicinal use, ritual use, or religious aspects), b) the pharmacological assessment of recorded and collected medicinal species in a laboratory setting (so-called "bioactivity studies"), and c) drug discovery of pharmacologically active natural products via pharmacognostic approaches. These activities may be expanded to include community work, as we believe ethnopharmacologists should also act as advocates for the respective indigenous communities with whom they collaborate.

Throughout history, the intellectual property rights of indigenous peoples have not been recognized, and questions concerning the ownership of biodiversity following the development and commercialization of pharmaceuticals have arisen. The Nagoya Protocol and the Convention on Biological Diversity provided international agreements on financial benefit sharing and recognized each nation's sovereignty over the biodiversity resources within its borders (Alexiades \& Sheldon, 1996; Balick \& Cox, 2020; Heinrich \& Jäger, 2015; Heinrich et al., 2018). But what about non-monetary benefits? What about the transfer of knowledge in both directions? Unfortunately, even today, 
ethnopharmacologists rarely return to the local communities after a study has been completed and published (Maregesi et al., 2007; Fabien Schultz, Godwin Anywar, Barbara Wack, et al., 2020). Thus, the successful collection of plant samples and ethnopharmacological information from traditional healers and other community members often marks the end point of this one-sided collaboration, despite the fact that this data will still be analyzed, interpreted, and published (see Figure 1). This problem was previously addressed in a book by Herman et al. (Herman et al., 2018).

Laboratory studies may follow, leading to unique significant discoveries that would certainly be of interest to the local study participants and could even empower them locally while fostering an equal partnership (Cordell, 1995; Unander et al., 1995; Vandebroek et al., 2011). If the scientists ever return, then in many cases it is only because of an entirely new study, aimed at extracting new information for their research. We believe that ethnopharmacologists therefore have the great responsibility of keeping this collaboration and the communication with their local informants bidirectional. Information and knowledge should be shared, creating a benefit for both the scientists and the local study participants.

\subsection{Previous Ethnopharmacological Studies}

In this video article, we would like to introduce a method for transferring the results of laboratory analyses and ethnobotanical surveys back to traditional healers. Our approach is based on a two-day workshop, using our previous

\section{Ethnopharmacological research}

Objectives: Documentation and assessment of traditional use, community work \& drug discovery

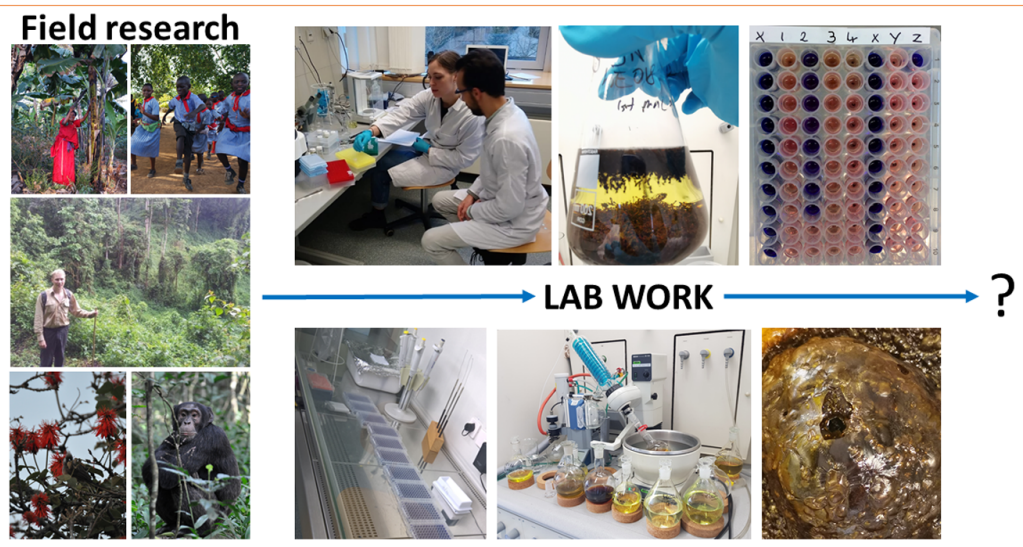

FIGURE 1 Objectives of ethnopharmacological research, showing the fieldwork and laboratory steps. But what comes next? 
studies from the Greater Mpigi region in Uganda as an example. A total of 16 medicinal plant species were investigated as part of an ethnobotanical survey among 39 traditional healers from the Greater Mpigi region. This past study has recently been published in the Journal of Ethnopharmacology (Fabien Schultz, Godwin Anywar, Barbara Wack, et al., 2020). Traditional healers from 29 different villages, including one from a small island in Lake Victoria, were interviewed. The study involved the first-time documentation of preparation and administration methods and the identification of a total of 75 medical disorders that are treated with these medicinal plants. In this study, information was obtained using questionnaires that were specifically designed to collect in-depth data on each species. Figure 2 shows three photographs from this field study, giving examples of local plant diversity.

In another follow-up study that was published, we applied the Degrees of Publication (DoP) method as a novel tool for literature assessment in ethnopharmacological research (F. Schultz et al., 2020). There are numerous field assessment tools in use today. However, none of these tools are able to help researchers determine which species merit the costly laboratory studies that would be required for their further investigation, e.g., pharmacological assays and the isolation of bioactive natural product compounds. The introduction of the DoP method has filled this gap. In the context of the aforementioned ethnobotanical survey, the DoP method made it possible to classify six of the 16 medicinal plant species as "highly understudied" and three as "understudied."(F. Schultz et al., 2020)

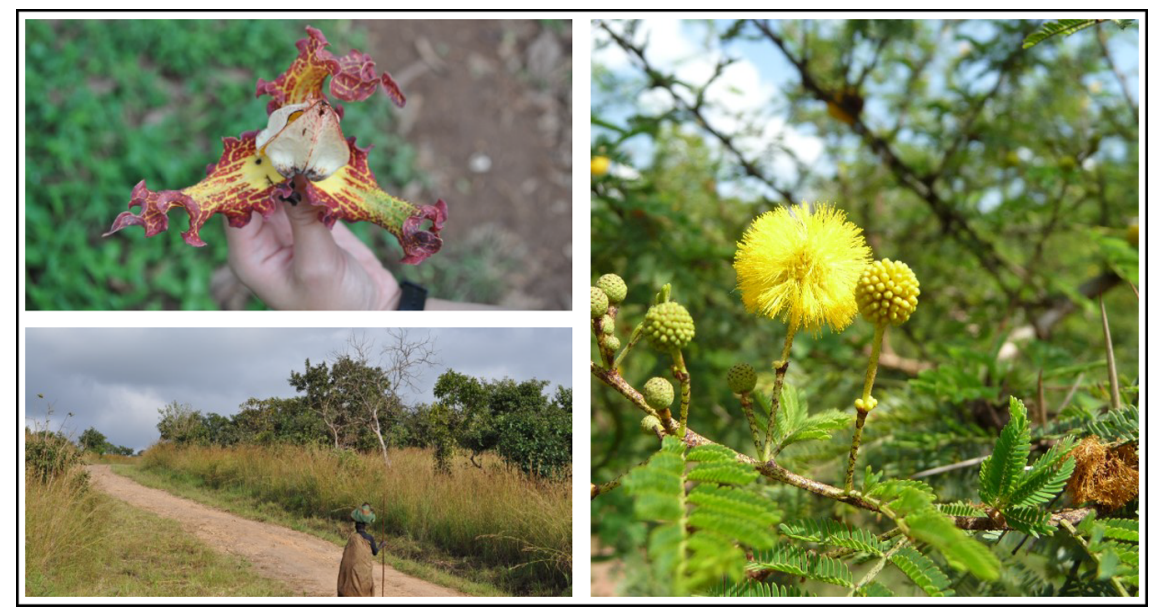

FIGURE 2 Illustrations of Ugandan plant diversity and traditional African community life 
At the Makerere University herbarium, taxonomic identification was accomplished based on the herbarium voucher specimens that were prepared during fieldwork. Following the fieldwork activities, samples of all 16 plant species were taken to the laboratory, where extracts were produced. Various pharmacological investigations followed on the basis of the use reports provided by the traditional healers (Schultz, Anywar, Tang, Chassange, Lyles, Garbe et al., 2020; Schultz, Osuji, Wack, Anywar \& Garbe, 2021; Schultz, Osuji, Wack, Anywar, Scheel et al., 2021). These included antimalarial, antibacterial, and antiinflammatory bioassays, among others (see Figure 3). These unique investigations led to a large number of interesting results.

During our fieldwork, we explicitly asked the 39 traditional healers about their motivation for collaborating with us (Fabien Schultz, Godwin Anywar, Barbara Wack, et al., 2020). The specific questions that we asked were: "What are your future expectations from our scientific findings, and what do you expect from us researchers?" Participants were invited to give multiple responses. Their answers were fascinating. Despite the fact that these traditional healers live in relatively poor circumstances, only $5 \%$ stated that they

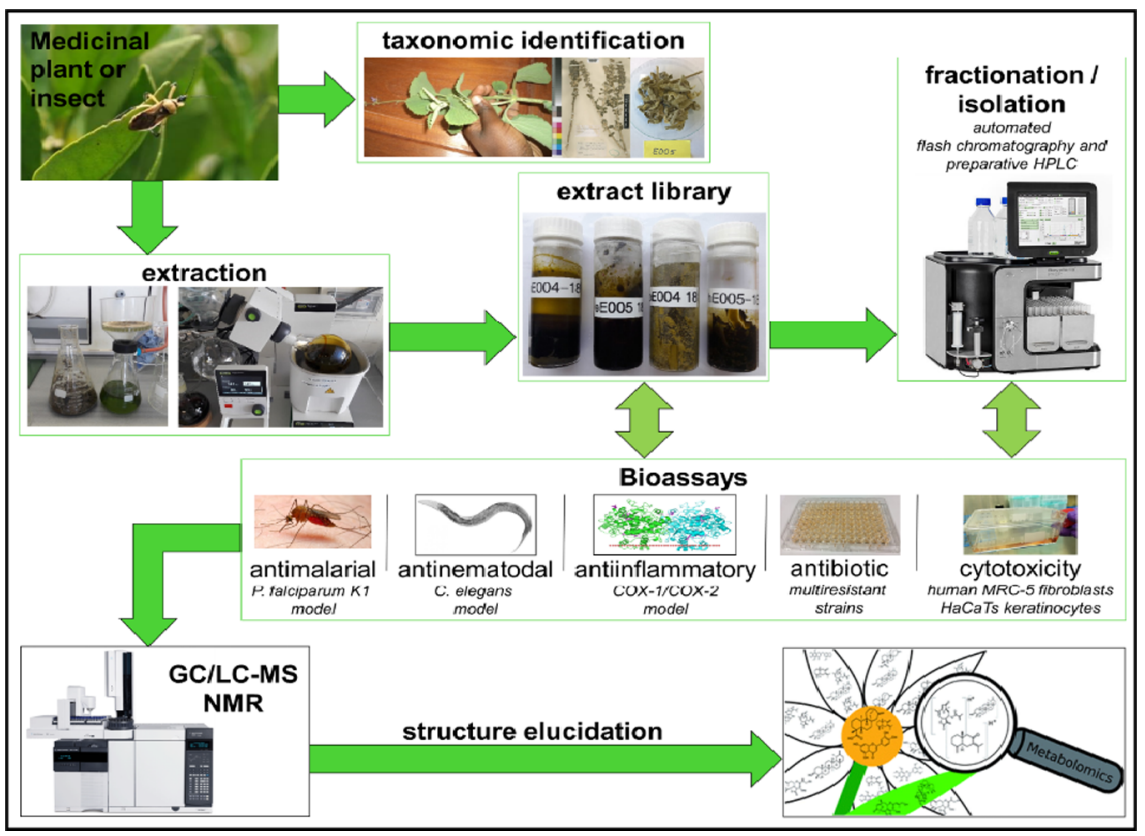

FIGURE 3 Illustration of our approach to ethnopharmacological lab studies aimed at the evaluation of traditional use and drug discovery; HPLC: high performance liquid chromatography, GC/LC-MS: gas chromatography/liquid chromatography-mass spectrometry, NMR: nuclear magnetic resonance spectroscopy 
would like to benefit financially from the scientific information gained. On the contrary, there was a high demand for feedback on the results of the survey and the laboratory studies, which we regard as the transfer of knowledge. The majority of the traditional healers said they would like to improve and continue their collaboration with us researchers. Nine percent were interested in a collaboration for improving their treatment of patients, and $11 \%$ wanted to strengthen their collaboration with us. The second most common expectation was to receive feedback on the findings of the pharmacological studies that followed the fieldwork. In addition, more than a quarter of the traditional healers mentioned that they would be interested in finding out whether scientific evidence could be found for the claimed medicinal properties of the investigated plants, as such evidence would boost their confidence in the respective treatments (Fabien Schultz, Godwin Anywar, Barbara Wack, et al., 2020). Their responses indicated that there is a vital need for feedback from ethnopharmacologists after a study is completed, as well as a strong interest in continued collaboration and participation in the research.

The results of the laboratory work and the ethnobotanical survey were shared with the traditional healers through a two-day workshop in November 2019. All of the traditional healers who had initially participated in the field study were invited to the workshop (Fabien Schultz, Godwin Anywar, Barbara Wack, et al., 2020). In order to contact them again, we used the network of the NGO pRoMETRA Uganda (www.prometraug.com). Together with PRoMETRA, we organized transport and food. The workshop took place at the local PROMETRA headquarters in Buyijja, Buwama sub county, in the Greater Mpigi region. Written informed consent for the filming and publishing of the video footage was requested and obtained from all participants shown in this video article. One of the possible reasons why so few scientific findings are transferred back to indigenous peoples and traditional healers is that scientific articles are often incomprehensible and inaccessible to them (Jaeger, 2005). Therefore, one major challenge was to explain the scientific results in a way that was appropriate to their level of understanding. Western researchers face the same challenge in the context of science outreach activities among the general public in their home countries. However, when such outreach activities are organized in other countries, there should also be an emphasis on cultural appropriateness. Our strategy for conveying complicated scientific results was to explain the assays and results figuratively and in a simplified manner, using everyday examples. 
Another challenge was the local language Luganda, which is why multiple translators were present at the workshop.

The workshop was divided into three parts:

- Day 1 (morning): Transfer of results in a classroom setting using a laptop and projector (results explanation)

- Day 1 (afternoon): Group discussion and questions from healers in the garden

- Day 2 (all day): Group visits to some of the healers' homes

The healers visited on Day 2 were traditional healers who had participated in another study within the Greater Mpigi region, and the video footage was intended as an example of how the bidirectional communication and continued collaboration could be established.

\section{$3 \quad$ Results}

The results from each of the three parts of the workshop were presented separately in the video article as video impressions.

\subsection{The Workshop}

3.1.1 Day 1 (Morning): Transfer of Results in a Classroom Setting Using a Laptop and Projector

For example, after we asked the workshop participants for permission to film them, one of the traditional healers asked us how the video would benefit them. Responses were given in the original video footage shown in the video article. During the first part, we presented the outcome of the initial questionnaires, as well as various results from our diverse lab studies (antimalarial, antiinflammatory, antivirulence, antibiotic, cytotoxicity, and genotoxicity assays). Figure 4 shows a photo of the organizer of the workshop, Fabien Schultz, and some of the 39 traditional healers during the results-explanation part of the workshop. The limitations of in vitro studies were explained during the presentation of lab results, along with the explanation that follow up studies were needed in the future in order to fully verify the pharmacological effects in vivo. The presented lab studies provided initial scientific evidence for the potential therapeutic efficacy of the medicinal plants used by the healers in the Greater Mpigi region. 


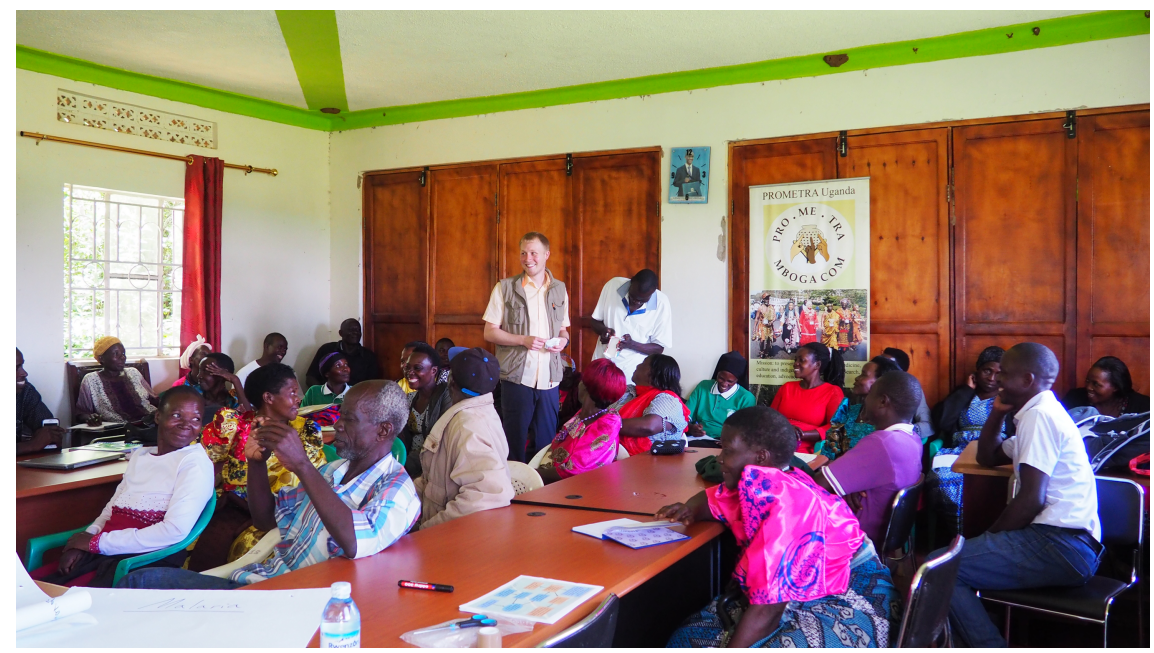

FIGURE 4 Photo illustrating the transfer of results in a classroom setting (day 1, workshop part 1) in the Garden

The traditional healers wanted to know more about the testing methods and what they could learn from them when it comes to preparing their medicines, which led to a very interesting discussion. The questions from the healers focused on the limitations of science, the scope of laboratory experiments, regional differences in the concentrations of active ingredients in plants, and even the role of spiritualism in traditional medicine. Figure 5 shows a picture from the group discussion under a tree in the garden.

\subsubsection{Day 2 (All Day): Group Visits to Some of the Healers' Homes}

This video footage gave impressions on how the traditional healers find and harvest some of the forest plants investigated in the laboratory studies, how they process these plants, how they sell them on the market, and how they treat patients. The group visits to their homes led to bidirectional communication, strengthening trust and interest in future collaborations. New research topics were identified via brainstorming methods, and traditional healers expressed their interest.

\subsection{The Broader Frame of the Study}

Within a wider frame, this study also addressed the open research movement and science communication strategies, in general, because the workshop method is an example for science outreach. According to a study by Iyengar \& Massey (2019), "gatekeeper" actors are a critical factor regarding "post-truth" 


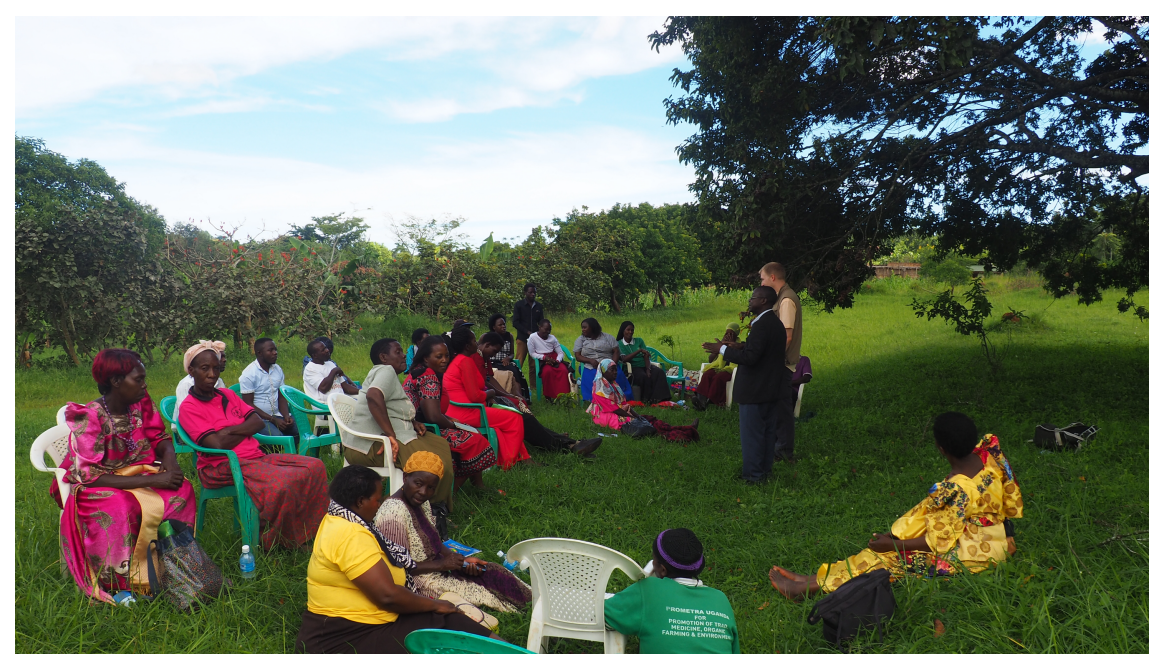

FIGURE 5 Photo showing the group discussion (day 1, workshop part 2)

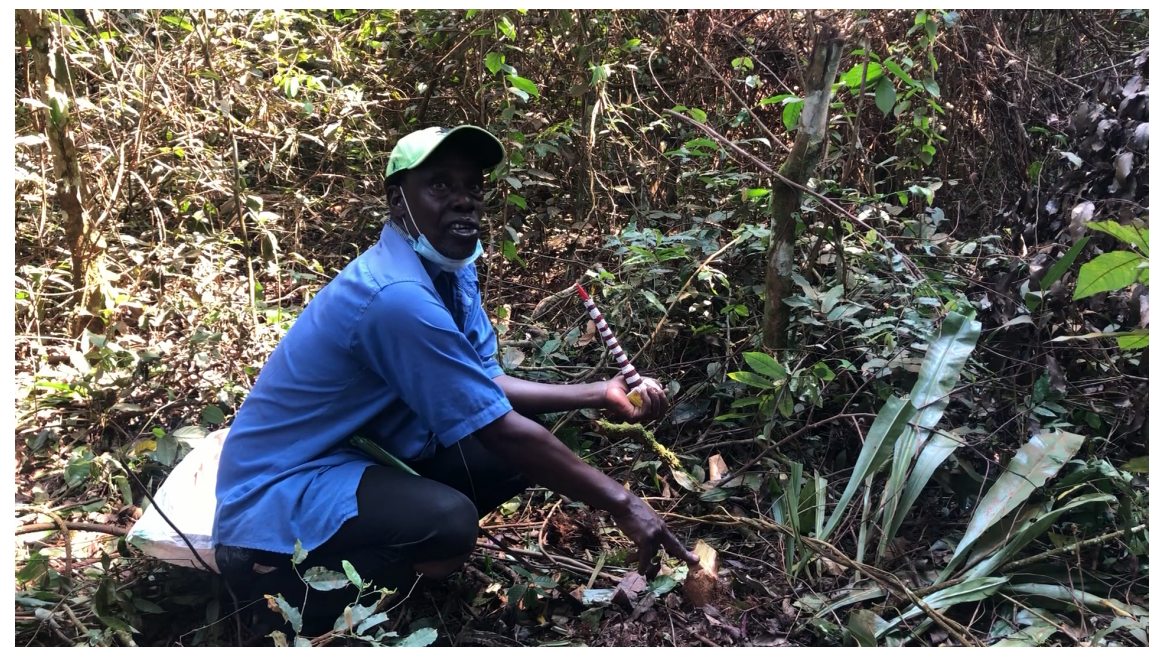

FIgURE 6 Traditional healer Ssalongo Kato Kkonde explains how to harvest Toddalia asiatica in the local forest (photo taken during visits to the homes of individual healers)

issues between researchers and the general public because they tend to manipulate information for different motives. In the study, the authors conclude that a direct and constructive communication between the general public and scientists can prevent "gatekeeper" actors from emerging and misinformation from being spread. Moreover, another study by Dyer et al. (2020) concluded that direct contact with scientists is more likely to enable public outreach of higher 
quality when it comes to important issues. Thus, the presented workshop, where participants strongly requested to receive expert scientific feedback on their traditional practices, helped to circumvent the emergence of misperceptions of scientific knowledge and distrust in the scientific undertaking.

Conducting a workshop for traditional healers and indigenous communities is an efficient way to transfer the results of ethnobotanical and ethnopharmacological studies back to local study participants. This video article, showing a workshop along with visits to some of the healers' homes, demonstrated a successful method of how bidirectional benefits and communication is possible as a starting point, fostering future scientific and community-work collaborations. Of course, our approach and workshop concept may not be suitable for all local and indigenous peoples, cultural backgrounds, or situations that may emerge during various aspects of ethnopharmacological research throughout the world. It is meant as an example, and as always, scientists' individual approaches need to be adapted to the given circumstances. What remains a fact is that very few scientific findings are transferred back to the traditional healers and indigenous peoples who originally laid the foundation for the advanced ethnopharmacological research endeavors. For example, it is possible that subsequent laboratory studies could even reveal that some medicinal plants pose a threat to local communities, because they are toxic and harmful to patients as a direct outcome of treatment. We believe that ethnopharmacologists should contribute to improving local herbal drug use, help reduce health hazards derived from medicinal plants, care and advocate for local communities, and create and maintain good relationships for future collaborations.

Consequently, we feel that ethnopharmacologists should commit to transferring the results of their studies back to their informants, for example, through medicinal plant workshops. Apart from that, the workshop method might also be regarded as a valuable contribution to research on education theory and science communication.

\section{Acknowledgements}

Our greatest thanks to the traditional healers who participated in the workshop, and to PвометRA Uganda for providing a location and a network of contacts within the previously surveyed communities. Thanks to student 
research assistants Ssemukasa Steven and Muyanja Joseph for assisting during the workshop. Special thanks to the Neubrandenburg University of Applied Sciences for supporting Fabien Schultz's fieldwork activities in Uganda in terms of working hours. We acknowledge support for the Article Processing Charge from the Association for Visual Pedagogies (AVP) and the Open Access Publication Fund of Neubrandenburg University of Applied Sciences (HSNB).

Author Contributions: Fabien Schultz (F.S.) designed the overall strategy of the study, conducted the workshop, and wrote the manuscript for this video article. Inken Dworak-Schultz (I.D.S.) edited the video, produced the voice-over, and acted as head of video production. F.S. and Godwin Anywar (G.A.) organized the workshop. I.D.S., G.A., and Alex Olengo (A.O.) filmed during the workshop, at the lab, and at the traditional healers' homes. A.O. translated the interviews from Luganda to English. F.S. and I.D.S. interpreted the video footage. Leif-Alexander Garbe directed the study. All of the authors watched, revised, and approved the final video article.

\section{Conflict of Interest}

Written informed consent was requested and obtained from all participants of the workshop and all participants shown in this video. The authors declare that the research was conducted in the absence of any commercial or financial relationships that could be construed as a potential conflict of interest. The content is solely the responsibility of the authors and does not necessarily reflect the official view of the funding agencies. The funding agencies had no role in the study design, data collection and analysis, decision to publish, or preparation of the manuscript/video article.

\section{References}

Alexiades, M. N., \& Sheldon, J. W. (1996). Selected Guidelines for Ethnobotanical Research: A Field Manual (Vol. 10). New York Botanical Garden.

Atanasov, A. G., Waltenberger, B., Pferschy-Wenzig, E.-M., Linder, T., Wawrosch, C., Uhrin, P., Temml, V., Wang, L., Schwaiger, S., Heiss, E. H., Rollinger, J. M., Schuster, D., Breuss, J. M., Bochkov, V., Mihovilovic, M. D., Kopp, B., Bauer, R., Dirsch, V. M., \& Stuppner, H. (2015). Discovery and resupply of pharmacologically active plantderived natural products: A review. Biotechnology Advances, 33(8), 1582-1614. https://www.doi.org/10.1016/j.biotechadv.2015.08.oo1. 
Balick, M.J., \& Cox, P. A. (2020). Plants, People, and Culture: The Science of Ethnobotany. CRC Press. https://www.doi.org/10.1201/9781003049074.

Balunas, M. J., \& Kinghorn, A. D. (2005). Drug discovery from medicinal plants. Life Sciences, 78(5), 431-441. https://www.doi.org/10.1016/j.lfs.2005.09.012.

Bussmann, R. W., Paniagua-Zambrana, N. Y., Wood, N., Ole Njapit, S., Ole Njapit, J. N., Ene Osoi, G. S., \& Kasoe, S. P. (2018). Knowledge Loss and Change Between 2002 and 2017 - a Revisit of Plant Use of the Maasai of Sekenani Valley, Maasai Mara, Kenya. Economic Botany, 72(2), 207-216. https://www.doi.org/10.1007/s12231-018-9411-9.

Cordell, G. A. (1995). Changing strategies in natural products chemistry. Phytochemistry, 4o(6), 1585-1612. https://www.doi.org/10.1016/oo31-9422(95)oo444-C.

Dyer, A. G., Howard, S. R., \& Garcia, J. E. (2020). Balancing research excellence and media impact: a multistage approach. Journal \& Proceedings of the Royal Society of New South Wales, 152, 320-326.

Heinrich, M. (2014). Ethnopharmacology: quo vadis? Challenges for the future. Revista Brasileira de Farmacognosia, 24, 99-102. http://www.scielo.br/scielo. php?script=sci_arttext\&pid=So102-695X2014000200099\&nrm=iso.

Heinrich, M., Barnes, J., Gibbons, S., \& Williamson, E. (2015). Importance of plants in modern pharmacy and medicine. Fundamentals of Pharmacognosy and Phytotherapy, 4-7.

Heinrich, M., \& Jäger, A. (2015). Ethnopharmacology. https://www.doi.org/10.1002/ 9781118930717 .

Heinrich, M., Lardos, A., Leonti, M., Weckerle, C., Willcox, M., Applequist, W., Ladio, A., Lin Long, C., Mukherjee, P., \& Stafford, G. (2018). Best practice in research: Consensus Statement on Ethnopharmacological Field Studies - ConSEFS. Journal of Ethnopharmacology, 211, 329-339. https://www.doi.org/10.1016/j.jep.2017.08.015.

Herman, R. D. K., Carter, J., Christensen, J., Colyer, C., Crew, D., D’Elia, E. A., Fadiman, M., Howitt, R., Hull, S., Isaac, G., Jacobson, C., Luze, M., MacKenzie, C. A., McChesney, L. S., McSweeney, K., Monk, J., Ornelas, R. T., Pearce, T., Reeves, M., Sakakibara, C., Shaw, W. S., Turner, S., \& Welch, J. R. (2018). Giving Back - Research and Reciprocity in Indigenous Settings.

Iyengar, S., \& Massey, D. S. (2019). Scientific communication in a post-truth society. Proceedings of the National Academy of Sciences, 116(16), 7656. https://www.doi. org/10.1073/pnas.1805868115.

Jaeger, A. K. (2005). Is traditional medicine better off 25 years later? Journal of Ethnopharmacology, 10o(1-2), 3-4. https://www.doi.org/10.1016/j.jep.2005.05.034.

Kigen, G., Kamuren, Z., Njiru, E., Wanjohi, B., \& Kipkore, W. (2019). Ethnomedical Survey of the Plants Used by Traditional Healers in Narok County, Kenya. EvidenceBased Complementary and Alternative Medicine, 2019, 8, Article 8976937. https:// www.doi.org/10.1155/2019/8976937. 
Li, F., Wang, Y., Li, D., Chen, Y., \& Dou, Q. P. (2019). Are we seeing a resurgence in the use of natural products for new drug discovery? Expert Opinion on Drug Discovery, 14(5), 417-420. https://www.doi.org/10.1080/17460441.2019.1582639.

Maregesi, S. M., Ngassapa, O. D., Pieters, L., \& Vlietinck, A. J. (2007). Ethnopharmacological survey of the Bunda district, Tanzania: Plants used to treat infectious diseases. Journal of Ethnopharmacology, 113(3), 457-47o. https://www.doi. org/10.1016/j.jep.2007.07.006.

Porras, G., Chassagne, F., Lyles, J. T., Marquez, L., Dettweiler, M., Salam, A. M., Samarakoon, T., Shabih, S., Farrokhi, D. R., \& Quave, C. L. (2020). Ethnobotany and the Role of Plant Natural Products in Antibiotic Drug Discovery. Chemical Reviews. https://www.doi.org/10.1021/acs.chemrev.ocoog22.

Schultz, F., Anywar, G., Quave, C. L., \& Garbe, L.-A. (2020). A bibliographic assessment using the Degrees of Publication method: Medicinal plants traditionally used in the rural Greater Mpigi region (Uganda) Evidence-Based Complementary and Alternative Medicine, in press. https://www.doi.org/10.1155/2020/6661565.

Schultz, F., Anywar, G., Tang, H., Chassagne, F., Lyles, J. T., Garbe, L. A., \& Quave, C. L. (2O2O). Targeting ESKAPE pathogens with anti-infective medicinal plants from the Greater Mpigi region in Uganda. Nature Scientific Reports, volume 10, Article number: 11935. https://www.doi.org/10.1038/s41598-020-67572-8.

Schultz, F., Osuji, F. O., Wack, B., Anywar, G., \& Garbe, L. A. Antiinflammatory Medicinal Plants from the Ugandan Greater Mpigi Region Act as Potent Inhibitors in the COX-2 / PGH2 Pathway. Plants, 10(2), 351, 2021; https://www.doi.org/10.339o/plants10020351. Schultz, F., Osuji, F. O., Wack, B., Anywar, G., Scheel, J., Caljon, G., Pieters, L., \& Garbe, L.-A. Pharmacological assessment of antiprotozoal activity, cytotoxicity and genotoxicity of medicinal plants used in treatment of malaria in the Greater Mpigi Region in Uganda. Frontiers in Pharmacology, 12:678535, 2021, https://www.doi. org/10.3389/fphar.2021.678535.

Schultz, F., Anywar, G., Wack, B., Quave, C. L., \& Garbe, L.-A. (2020). Ethnobotanical study of selected medicinal plants traditionally used in the rural Greater Mpigi region of Uganda. Journal of Ethnopharmacology, 256, 112742. https://www.doi. org/10.1016/j.jep.2020.112742.

Unander, D. W., Webster, G. L., \& Blumberg, B. S. (1995). Usage and bioassays in Phyllanthus (Euphorbiaceae). IV. Clustering of antiviral uses and other effects. Journal of Ethnopharmacology, 45(1), 1-18. https://www.doi. org/10.1016/o378-8741(94)o1189-7.

Vandebroek, I., Reyes-García, V., de Albuquerque, U. P., Bussmann, R., \& Pieroni, A. (2011). Local knowledge: Who cares? Journal of Ethnobiology and Ethnomedicine, 7(1), 35. https://www.doi.org/10.1186/1746-4269-7-35.

Veeresham, C. (2012). Natural products derived from plants as a source of drugs. Journal of Advanced Pharmaceutical Technology \& Research, 3(4), 200-201. https://www.doi. org/10.4103/2231-4040.104709. 
WHO. (2010). Guidelines for registration of traditional medicines in the WHO African Region. Regional Office for Africa(AF R/TRM/04.1), 11.

wHo. (2019). Health Topic - Traditional Medicine. Retrieved March 26th from https:// www.afro.who.int/health-topics/traditional-medicine.

Yuan, H., Ma, Q., Ye, L., \& Piao, G. (2016). The Traditional Medicine and Modern Medicine from Natural Products. Molecules (Basel, Switzerland), 21(5), 559. https:// www.doi.org/10.3390/molecules21050559. 